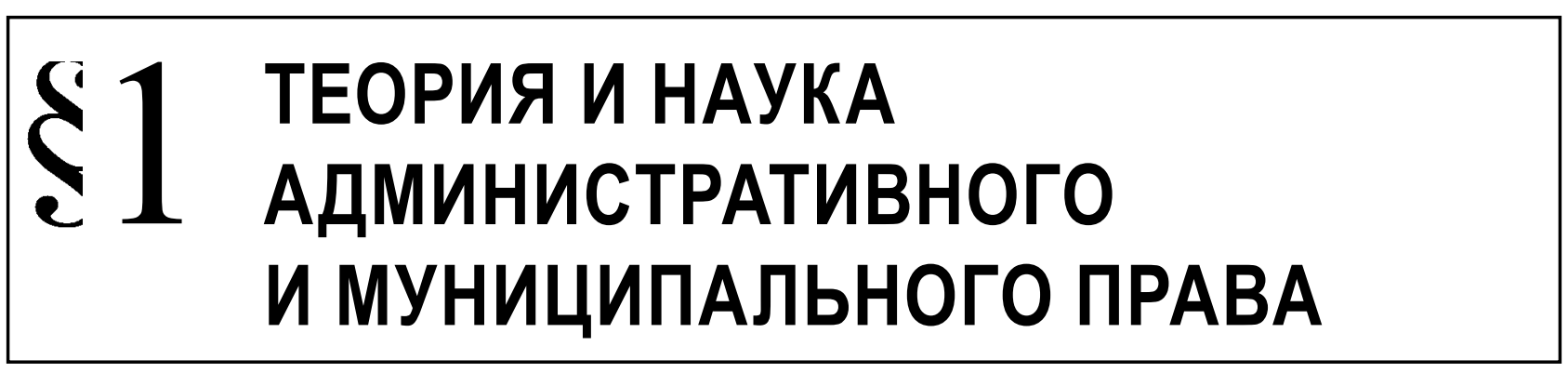

Карпов В.А.

\title{
О НЕКОТОРЫХ ЗАКОНОМЕРНОСТЯХ ПОСТРОЕНИЯ СИСТЕМЫ ПРАВ И СВОБОД ЧЕЛОВЕКА И ГРАЖДАНИНА В РОССИЙСКОЙ ФЕДЕРАЦИИ В КОНТЕКСТЕ РАЗВИТИЯ ПРАВОВОЙ ГОСУДАРСТВЕННОСТИ
}

Аннотация. Объектом исследования являются права и свободы человека и гражданина в Российской Федерации, которые рассматриваются с точки зрения общей теории систем как целостная взаимосвязанная система, выявляются внутренние закономерности ее развития, основные иерархические подсистемные уровни, некоторые механизмы системных связей. В статье на основе анализа отмечена историческая изменчивость научного и практического понимания системы прав и свобод человека и гражданина. Рассмотрены перспективы совершенствования конституционного закрепления системы прав и свобод человека и гражданина в Российской Федерации в контексте развития российской правовой государственности. Методологическую основу исследования составляет диалектический метод познания действительности, совокупность общенаучных (логического, восхождения от абстрактного к конкретному в мышлении и т.д.) и частнонаучных методов познания (сравнительного правоведения, системно-структурного анализа, толкования закона и других). Научная новизна проведенного исследования заключается в обосновании преждевременности совершенствования Конституции с точки зрения совершенствования конституционного закрепления системы прав и свобод человека и гражданина в России, а также рассмотрены перспективы совершенствования конституционного закрепления системы прав и свобод человека и гражданина в контексте развития российской правовой государственности.

Ключевые слова: права и свободы, человек, гражданин, система прав, основные подсистемы прав, системные связи, правовая государственность, совершенствование Конституции, иерархия, принцип ограничения.

Review. The article focuses on rights and freedoms of man and citizen in the Russian Federation which are considered from the standpoint of the general systems theory as an integral interrelated system; the author reveals the internal patterns of its development, the key hierarchical sub-system levels, and some mechanisms of the system links. On the base of the analysis the article considers the historical mutability of the scientific and practical understanding of the system of rights and freedoms of man and citizen. The author analyzes the perspectives of enhancement of constitutional legalization of the system of rights of man and citizen in the Russian Federation in the context of the Russian legal statehood development. The methodology of the research is based on the dialectical method of reality cognition, and the set of the general scientific methods (the logical method, an abstract to concrete shift in thinking, etc.) and the special scientific methods of cognition (comparative jurisprudence, the systems and structural analysis, interpretation of law, etc.). The scientific novelty of the research lies in the substantiation of untimeliness of the Constitution enhancement from the standpoint of the constitutional legalization of the system of rights and freedoms of man and citizen in Russia. The author also assesses the perspectives of enhancement of constitutional legalization of this system of rights in the context of development of the Russian legal statehood.

Keywords: rights and freedoms, man, citizen, system of rights, main sub-systems of rights, system links, legal statehood, enhancement of the Constitution, hierarchy, limitation principle.

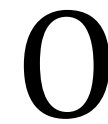
собая важность эффективного конституционного закрепления системы прав и свобод человека и гражданина в современной
России связана с тем, что именно они выступают одним из наиболее действенных ограничителей государства в правовой сфере. Именно принцип 
ограничения государства правом является квинтэссенцией концепции правовой государственности. По справедливому замечанию В.Т. Кабышева, «права и свободы человека в аспекте соотношения человека и государства - это своеобразный предел осуществления государственной власти, критерий развитости и цивилизованности общества» $[1$, C.70].

Однако, несмотря на важность прав и свобод человека и гражданина для построения правовой государственности, они по-прежнему во многом рассматриваются как простая совокупность прав, без учета их тесной системной взаимосвязи. Между тем права и свободы человека и гражданина необходимо исследовать и с точки зрения общей теории систем как целостная система, во всем многообразии ее внутрисистемных связей.

Как известно, согласно постулатам общей теории систем, от простой совокупности систему отличает наличие особых интегративных свойств, которыми элементы системы не обладают по отдельности, но приобретают, объединившись. Представляется, что таким интегративным свойством для системы прав человека является способность выступать гарантией правовой государственности и создавать эффективный механизм обеспечения достойного существования человека в современном государстве на всех основных бытийных уровнях. Этого могут достигнуть только все права и свободы человека и гражданина в комплексе например, отсутствие в их системе политических прав даже при довольно развитых социальных правах не создает в полной мере правовой государственности в современном ее понимании.

Каждая сложная система включает в себя ряд подсистем - иерархических внутренних структур различного порядка. Система прав и свобод человека и гражданина в Российской Федерации также включает ряд подсистем, которые образуют внутреннюю структуру данной системы, объединенную системными связями. Рассмотрим основные из этих подсистем.

1) Деление системы прав и свобод человека и гражданина на подсистемы личных, политических, социально-экономических, культурных прав и свобод человека и гражданина.

Названные подсистемы являются объективно сформировавшимися в ходе поступательного эволюционного развития системы прав и свобод человека и гражданина по принципу «предметного центра притяжения» образования системных связей.
Границы подсистем являются подвижными, динамичными. Каждый элемент подсистемы множеством системных связей объединен со множеством других элементов как самой системы, так и ее непосредственного правового и социального окружения. Понимание прав и свобод человека и гражданина как объективно сформировавшейся системы, развитие которой подчиняется самообусловленным внутренним закономерностям, не позволяет считать указанные подсистемы лишь формальной научной классификационной градацией, в которой каждый элемент может быть строго отнесен только лишь к одной классификационной единице.

Понимание прав и свобод человека и гражданина с точки зрения общей теории систем позволяет объяснить трудности с определением места ряда прав и свобод в структуре системы, которое отмечают многие современные исследователи. Например, И.Н. Плотникова, исследуя право на предпринимательскую деятельность, пишет: «это конституционное право обладает как частноправовым (в большей степени), так и публично-правовым содержанием. Подчеркивается, что право на предпринимательскую деятельность можно отнести как к группе личных прав, так и экономических прав. Применительно к странам Восточной Европы и государствам СНГ, исходя из их исторического прошлого и необходимости государственного содействия в реализации права на предпринимательскую деятельность, является закономерным отнесение данного права к числу позитивных, входящих в группу социально-экономических прав» [2, С. 8]. По мнению П.В. Горбачева, «конституционное право граждан Российской Федерации на благоприятную окружающую среду относится к категории как личных, так и социально-экономических прав индивида. Кроме того, в настоящее время оно имеет отношение и к политическим правам граждан. Субъективное право граждан на благоприятную окружающую среду, принадлежащее к новому поколению прав личности, включает в себя целый комплекс более конкретных прав граждан в области охраны здоровья и природопользования. В то же время его следует рассматривать в качестве важнейшего элемента более объемного естественного права человека - права на благоприятную среду обитания» [3, С. 8-10].

2) Деление системы прав и свобод человека и гражданина на различные поколения (волны).

Выделение данных подсистем также основывается на объективных закономерностях исто- 
рического развития всей системы. Вместе с тем, рассмотрение системы прав и свобод человека и гражданина как сугубо научной классификации, в отрыве от ее внутренних тенденций и закономерностей, зачастую приводит ученых к не вполне оправданным выводам. Например, выдвигаются несколько умозрительные критерии выделения нового поколения прав и свобод человека и гражданина, основанные только лишь на научных, абстрактных доводах.

В связи с этим приведем мнение Р.И. Ахметшина, позицию которого мы разделяем: «Классификация прав человека, принятая сторонниками концепции «третьего поколения прав человека», представляется весьма неудачной. В диссертации (Р.И. Ахметшина - авт.) отмечается сомнительность как самого термина «поколение», так и, что более существенно, предложенных критериев для выделения третьего поколения прав человека в отдельную категорию, отличную от гражданских, политических, экономических, социальных и культурных прав. Индивидуальная природа не является существенным признаком прав человека, и в отдельных случаях обладателями этих прав могут быть социальные коллективы. Это подтверждается, во-первых, документами международного и национального права в области защиты прав и свобод человека, которые содержат указания на права отдельных социальных коллективов (таких как народ, меньшинство, семья) и на обязанности государств по уважению этих прав, и, во-вторых, развитием общей доктрины прав человека, которая в целом допускает существование иных, нежели индивид, субъектов этих прав» [4, С. 3].

3) Деление системы прав и свобод человека и гражданина на подсистему прав человека и гражданина и подсистему свобод человека и гражданина.

Указанные подсистемы имеют наиболее зыбкую и нечеткую границу между собой, поскольку развиваются согласно общим закономерностям. Фактически, на практике подсистема прав и подсистема свобод сливаются между собой в единое целое, поскольку их выделение носит в большей степени научно-классификационный, доктринальный характер. В научных исследованиях высказана следующая точка зрения, согласно которой «как и во всех документах, содержащих международные нормы в области прав человека, в Конституции и законах Российской Федерации встречаются понятия «права человека» и «свободы человека», которые по своей юридической природе и системе гарантий в общем одинаковы. Хотя слово «свобода» встречается в положениях Конституции, подчеркивающих более широкие возможности выбора, не указывая конкретного результата (свобода: мысли, слова, совести, вероисповедания, убеждений, выбора рода деятельности и профессии и другие), провести существенное различие между словами «права» и «свободы» довольно сложно» [5, С. 4-5].

4) Деление системы прав и свобод человека и гражданина на подсистему прав и свобод человека и подсистему прав и свобод гражданина.

В целом о данном делении можно сказать то же, что о предшествующем - на практике обе эти подсистемы проявляют общие закономерности, различаясь лишь по кругу субъектов.

Система прав и свобод человека и гражданина в России имеет сложное иерархическое внутреннее строение (структуру). Помимо подсистем второго порядка, в нее в качестве иерархических уровней входят и подсистемы третьего порядка. В частности, многие современные авторы выделяют ряд системных уровней в рамках той или иной отмеченной выше подсистемы. Например, Н.С. Бондарь представляет социально-экономические права в виде системного единства (совокупности) следующих групп прав: 1) рыночно-экономические права и свободы, обеспечивающие свободу предпринимательской деятельности и иных форм экономической, трудовой деятельности; 2) социально-культурные права и свободы, способствующие духовному развитию граждан; 3) социальные права, гарантирующие человеку достойную жизнь, защиту от негативных воздействий рынка; 4) социальные права-гарантии, обеспечивающие нормальное физиологическое развитие личности [6, С. 186]. По мнению Г.В. Антиповой, «основанием классификации личных прав и свобод может служить объект правового регулирования. По этому критерию личные права и свободы подразделяются на три группы: во-первых, личные права, обеспечивающие физическую и психическую неприкосновенность; во-вторых, личные права, обеспечивающие нравственную ценность личности; в-третьих, личные права, обеспечивающие свободу личности» $[7$, С.9].

Для многих систем характерно наличие так называемого «системного ядра», системообразующего элемента, вокруг которого группируются системные связи. В системе прав и свобод человека и гражданина также можно выделить подобное системное ядро. Например, 3.В. Зекалашвили относит к системообразующим элементам системы прав человека в Российской Федерации следующие: «Жизнь, свобода, равноправие, демократия» 
[8]. Такая позиция представляется спорной с точки зрения отнесения всего перечисленного именно к правам, скорее речь идет о ценностях, которые, тем не менее, обеспечиваются каждая целым комплексом прав и свобод. Однако общий настрой на поиск внутрисистемных закономерностей в системе прав и свобод человека и гражданина следует приветствовать.

Между элементами системы прав и свобод человека и гражданина существуют сложные системные связи. Например, как отмечают исследователи, «право человека и гражданина на информацию тесно связано с остальными конституционными правами и свободами человека и гражданина; оно выступает как одна из гарантий их реализации (право на благоприятную окружающую среду и достоверность информации о ее состоянии, избирательного права), другие права и свободы в свою очередь играют роль гарантий реализации этого права (свобода мысли и слова, свобода массовой информации)» [9, С. 9].

Еще один характерный пример - диалектика взаимосвязи свободы творчества и преподавания и свободы совести. В частности, в правовой литературе высказано предложение рассматривать свободу литературного, художественного, научного и других видов творчества, преподавания как один из способов реализации гражданами и их объединениями свободы совести в широком смысле слова, которая в сочетании со свободой совести в узком смысле слова образует конституционно-правовой институт интеллектуальной (мировоззренческой) свободы [10, С. 7-8].

Находясь в динамическом живом взаимодействии, права и свободы человека и гражданина могут вступать во взаимоотношения не только соподчинения или корреляции, но и конкуренции. Например, как отмечается в правовой науке, «институт авторского права также может являться своеобразным ограничением права человека и гражданина на информацию. Сущность этого права заключается в том, что лицо, обладающее авторским правом на произведения литературы и искусства, а также на изобретения, может распоряжаться ими и сведениями, содержащимися в них, по своему усмотрению. Это означает, что такие произведения не могут быть изданы, публично исполнены или другим образом использованы без согласия автора» $[9$, С. 9].

Подобная конкуренция является довольно острой проблемой для правоприменительной практики, особенно в рамках конституционного правосудия. Представляется, что конкуренцию прав и свобод человека и гражданина целесообразно разрешать, исходя из приоритетных целей и задач построения правовой государственности, в историческом контексте конкретной ситуации их конкуренции.

Необходимо отметить историческую изменчивость научного и практического понимания системы прав и свобод человека и гражданина. Например, в советский период развития науки государственного права и государственно-правовой практики подчеркивалось строгое разграничение советской системы прав и свобод человека и гражданина и буржуазной системы прав и свобод человека и гражданина. Советскими учеными отстаивалась следующая точка зрения: «В.И. Ленин еще в 1919 году предупреждал, что капитализм «против нас выдвинет знамя свободы». Игнорируя социалистическое решение взаимоотношений личности и общества, буржуазная политическая и правовая идеология пытается «монополизировать» свободу и демократию, отрицая тем самым общечеловеческую ценность демократических политических и юридических институтов и учреждений; активно ведется кампания в «защиту прав человека», искажается действительное содержание прав и обязанностей человека в социалистическом обществе. Этим предопределяется значение содержательного анализа социалистической концепции прав и обязанностей человека, активной пропаганды социалистических ценностей и идеалов, преодоления буржуазных интерпретаций положения личности в социалистическом обществе и государстве в противостоянии двух противоположных идеологий» $[11$, С. 3-4].

В настоящее время, в современную эпоху глобализации и правовой интернационализации, в науке утверждается представление о единых общечеловеческих стандартах прав и свобод человека и гражданина. Однако и в рамках данной концепции находит место тезис об исторической изменчивости понимания тех или иных прав и свобод. Принцип исторического развития системы прав и свобод человека и гражданина неизбежно подразумевает, что закрепленная в настоящее время в Конституции Российской Федерации система прав и свобод не является раз и навсегда данной, застывшей в своей неизменности. Принцип правовой государственности, задачи построения правового государства в России диктуют необходимость постоянного совершенствования системы прав и свобод человека и гражданина в нашей стране и 
гарантий ее реализации. До определенного периода совершенствование нормативного закрепления данной системы может осуществляться с использованием законодательных и подзаконных механизмов, механизма судейского толкования права. Однако неизбежно наступит исторический момент, когда данных ресурсов развития системы уже не будет хватать, и на повестку дня встанет вопрос о совершенствовании главной нормативной основы системы прав и свобод человека и гражданина в Российской Федерации - Конституции.

Уже сейчас в правовой науке выдвигаются различные предложения по совершенствованию конституционного закрепления системы прав и свобод человека и гражданина в России. Р.И. Ахметшин справедливо отмечает: «необходимо учитывать как постоянное развитие доктрины в отношении прав человека и их защиты, так и происходящие во многих странах демократические процессы, которые выдвигают все новые и новые требования к государствам. Постепенно происходит признание новых прав, которые становятся «естественными и неотъемлемыми», растет количество общепризнанных прав человека, уважать и защищать которые обязаны все государства. При этом конкретизируется содержание как давно закрепленных, так и только что провозглашенных прав, различные аспекты этих прав подвергаются анализу и нормативному закреплению» [12, С. 3].

Например, Н.А. Грачев считает, что «с развитием общества, цивилизации и культуры интеллектуальная деятельность будет приобретать все более заметное значение в экономике. Поэтому право собственности на результаты интеллектуальной деятельности, безусловно, должно быть защищено Конституцией и другими законами. В связи с тем что интеллектуальная деятельность играет и будет играть важнейшую роль в экономических отношениях, право интеллектуальной собственности должно быть защищено теми же способами и средствами, что и экономические права» [13].

По мнению П.В. Горбачева, «отношения, возникающие в сфере реализации права на благоприятную окружающую природную среду, ха- рактеризуются отсутствием должной правовой регламентации. В связи с этим предлагается следующая редакция ст. 42 Конституции: «Каждый имеет право на благоприятную окружающую среду. Каждый имеет право на достоверную информацию о ее состоянии и право участвовать в принятии решений, влияющих на состояние биосферы России. Государство гарантирует каждому возмещение ущерба, причиненного его здоровью или имуществу экологическим правонарушением» [3].

С.А. Широбоков приходит к выводу о том, что «конституционное закрепление права граждан на обращение в нашей стране не совсем полно отражает его объективную необходимость, не соответствует времени и не способствует дальнейшему развитию общения граждан с государством и его органами. Внесено предложение - расширить содержание ст. 33 Конституции, включив следующий текст: «Государство гарантирует право граждан на объективное, всестороннее рассмотрение их обращений компетентным органом в установленный срок, обеспечивает привлечение к ответственности лиц, чьи действия и решения стали причиной нарушения прав и свобод граждан, и компенсацию причиненного ущерба» [14, С. 9].

Однако в настоящее время законодательные и подзаконные способы развития системы прав и свобод человека и гражданина в Российской Федерации еще не исчерпали своего потенциала. Интересы стабильности развития российской правовой государственности требуют разумной незыблемости текста Конституции Российской Федерации как основы построения правового государства. В связи с этим, полагаем, внесение существенных изменений в нормы Конституции Российской Федерации, закрепляющие систему прав и свобод человека и гражданина, является несколько преждевременным. Вместо обновления конституционной регламентации следует совершенствовать практические гарантии реализации прав и свобод и способствовать эффективному использованию гражданами всех предоставленных действующим законодательством способов и механизмов реализации конституционных прав и свобод.

\section{Библиография:}

1. Кабышев В.Т. Российский конституционализм на рубеже тысячелетий // Правоведение. 2001 . №4.

2. Плотникова И.Н. Конституционное право человека и гражданина на предпринимательскую деятельности в России: Автореф. дисс. ...канд. юрид. наук. Саратов, 2002.

3. Горбачев П.В. Право человека на благоприятную окружающую среду в контексте соотношения законодательства Российской Федерации и международных стандартов: Автореф. дисс. ...канд. юрид. наук. М., 1995.

4. Ахметшин Р.И. К проблеме третьего поколения прав человека: Автореф. дисс. ...канд. юрид. наук. М., 1999. 
5. Горшкова С.А. Европейская Конвенция о защите прав человека и основных свобод и правовая система Российской Федерации: Автореф. дисс. ...канд. юрид. наук. М., 1998.

6. Бондарь Н.С. Права человека и Конституция РФ. Ростов-на-Дону, 1998.

7. Антипова Г.В. Система личных прав человека: Конституционно-правовой аспект: Автореф. дисс. ...канд. юрид. наук. М., 2002.

8. Зекалашвили 3.В. Конституционная защита системообразующих прав человека в Российской Федерации: Жизнь, свобода, равноправие, демократия: Автореф. дисс. ...канд. юрид. наук. М., 1999.

9. Хижняк В.С. Конституционное право человека и гражданина на информацию в Российской Федерации: Автореф. дисс. ...канд. юрид. наук. Саратов, 1998.

10. Черемных Г.Г. Право человека на свободу совести в условиях формирования гражданского общества в Российской Федерации: Автореф. дисс. ...канд. юрид. наук. СПб., 1996.

11. Эбзеев Б.С. Конституционные проблемы прав и обязанностей человека в советском обществе: Автореф. дисс. ... докт. юрид. наук. Свердловск, 1989.

12. Ахметшин Р.И. К проблеме третьего поколения прав человека: Автореф. дисс. ...канд. юрид. наук. М., 1999.

13. Грачев Н.А. О видах и месте конституционных экономических прав и свобод человека и гражданина в системе прав и свобод // Конституционное и муниципальное право. 2006. № 8.

14. Широбоков С.А. Конституционное право человека и гражданина на обращение: Автореф. дисс. ...канд. юрид. наук. Екатеринбург, 1999.

\section{References (transliterated):}

1. Kabyshev V.T. Rossiiskii konstitutsionalizm na rubezhe tysyacheletii // Pravovedenie. 2001. №4.

2. Plotnikova I.N. Konstitutsionnoe pravo cheloveka i grazhdanina na predprinimatel'skuyu deyatel'nosti v Rossii: Avtoref. diss. ...kand. yurid. nauk. Saratov, 2002.

3. Gorbachev P.V. Pravo cheloveka na blagopriyatnuyu okruzhayushchuyu sredu v kontekste sootnosheniya zakonodatel'stva Rossiiskoi Federatsii i mezhdunarodnykh standartov: Avtoref. diss. ...kand. yurid. nauk. M., 1995.

4. Akhmetshin R.I. K probleme tret'ego pokoleniya prav cheloveka: Avtoref. diss. ...kand. yurid. nauk. M., 1999.

5. Gorshkova S.A. Evropeiskaya Konventsiya o zashchite prav cheloveka i osnovnykh svobod i pravovaya sistema Rossiiskoi Federatsii: Avtoref. diss. ...kand. yurid. nauk. M., 1998.

6. Bondar' N.S. Prava cheloveka i Konstitutsiya RF. Rostov-na-Donu, 1998.

7. Antipova G.V. Sistema lichnykh prav cheloveka: Konstitutsionno-pravovoi aspekt: Avtoref. diss. ...kand. yurid. nauk. M., 2002.

8. Zekalashvili Z.V. Konstitutsionnaya zashchita sistemoobrazuyushchikh prav cheloveka v Rossiiskoi Federatsii: Zhizn', svoboda, ravnopravie, demokratiya: Avtoref. diss. ...kand. yurid. nauk. M., 1999.

9. Khizhnyak V.S. Konstitutsionnoe pravo cheloveka i grazhdanina na informatsiyu v Rossiiskoi Federatsii: Avtoref. diss. ... kand. yurid. nauk. Saratov, 1998.

10. Cheremnykh G.G. Pravo cheloveka na svobodu sovesti v usloviyakh formirovaniya grazhdanskogo obshchestva v Rossiiskoi Federatsii: Avtoref. diss. ...kand. yurid. nauk. SPb., 1996.

11. Ebzeev B.S. Konstitutsionnye problemy prav i obyazannostei cheloveka v sovetskom obshchestve: Avtoref. diss. ...dokt. yurid. nauk. Sverdlovsk, 1989.

12. Akhmetshin R.I. K probleme tret'ego pokoleniya prav cheloveka: Avtoref. diss. ...kand. yurid. nauk. M., 1999.

13. Grachev N.A. O vidakh i meste konstitutsionnykh ekonomicheskikh prav i svobod cheloveka i grazhdanina v sisteme prav i svobod // Konstitutsionnoe i munitsipal'noe pravo. 2006. № 8.

14. Shirobokov S.A. Konstitutsionnoe pravo cheloveka i grazhdanina na obrashchenie: Avtoref. diss. ...kand. yurid. nauk. Ekaterinburg, 1999. 